\title{
THE INTERACTION OF THYROXINE WITH PLASMA PROTEINS: LOCALIZATION OF THYROXINE-BINDING PROTEIN IN COHN FRACTIONS OF PLASMA ${ }^{1,2}$
}

\author{
By NORBERT FREINKEL, ${ }^{3}$ J. THOMAS DOWLING, AND SIDNEY H. INGBAR
}

(From the Thorndike Memorial Laboratory, Second and Fourth Medical Services (Harvard), Boston City Hospital, and the Department of Medicine, Harvard Medical School, Boston, Mass. and the Howard Hughes Medical Institute)

(Submitted for publication June 17, 1955; accepted July 28, 1955)

Recently zone electrophoretic techniques have been employed to characterize the site of thyroxine-binding in plasma (1-7). In most reports, an association has been described between thyroxine and a protein moiety intermediate in electrophoretic mobility at $\mathrm{pH} 8.6$ between the $\alpha_{1}$ and the $\alpha_{2}$ globulins.

A concentrated source of this thyroxine-binding protein (TBP) has not been available for further purification or for experimental evaluation of its physiological role. To meet these objectives, zone electrophoretic techniques have been employed to localize TBP in subfractions of plasma prepared by Method 6 of Cohn and his co-workers $(8,9)$.

\section{MATERIALS}

1. Cohn Fractions: Fractions were obtained from 250 milliliters of fresh plasma and from 100 liters of plasma derived from out-dated blood-bank blood. Two separate fractionations were performed with ethanol-water mixtures of controlled $\mathrm{pH}$, ionic strength, temperature, and protein concentration. Yields from the large-scale fractionation of old plasma were sufficient to permit characterization of the individual fractions by moving-boundary electrophoresis and by chemical estimation of iodine/ nitrogen ratios (Table I).

2. Thyroxine: Chromatographically-pure $\mathrm{I}^{181}$-labelled thyroxine (10), dissolved in propylene glycol was obtained from a commercial source. ${ }^{4}$ Gravimetrically de-

\footnotetext{
1 This investigation was supported in part by research grant No. A-267 from the National Institute of Arthritis and Metabolic Diseases of the National Institutes of Health, Public Health Service and in part by the Medical Research and Development Board, Office of the Surgeon General, Department of the Army, under Contract No. DA-49-007-MD-412.

2 Presented in part at the 1955 meeting of the Endocrine Society, June 2-4, 1955, Atlantic City, New Jersey.

${ }^{3}$ Fellow of the American Cancer Society, Inc. recommended by the Committee on Growth of the National Research Council.

4 Abbott Laboratories, Oak Ridge, Tenn.
}

termined amounts of unlabelled L-thyroxine sodium 5 were added to vary specific activity.

\section{METHODS}

1. Free electrophoresis: ${ }^{8}$ Cohn Fractions were dissolved in barbital buffer, $\mathrm{pH} 8.6$, ionic strength 0.1 . Two gram per cent solutions were dialyzed against barbital buffer at $5^{\circ} \mathrm{C}$. Free moving boundary electrophoresis was performed in a Klett Electrophoresis Apparatus and photographs were obtained with a moving diaphragm scanning method. Pictures were enlarged and analyzed by dropping perpendiculars from the lowest points and measuring the areas under the peaks in the magnified schlieren diagrams.

2. Chemical analyses: Protein-bound iodine (PBI) was determined by a modification of the alkaline ash method of Barker ${ }^{7}$ (11). Wet digestion was employed

5 This was 96.2 per cent pure on a dry basis and kindly supplied by Dr. A. E. Heming of Smith, Kline \& French Laboratories, Philadelphia, $\mathrm{Pa}$.

${ }^{6}$ Analyses performed in the laboratory of Dr. John M. Newell of the Massachusetts Public Health Biologic Laboratories, Jamaica Plain, Mass.

${ }^{7}$ Iodine analyses were performed by Bio-Science Laboratories, Inc., 2231 Carmelina Avenue, Los Angeles 64, Calif.

TABLE I

Moving boundàry electrophoresis and iodine analyses of Cohn Fractions

\begin{tabular}{cccccccc}
\hline \hline & \multicolumn{7}{c}{ Electrophoretic composition (per cent) } \\
\cline { 2 - 7 } Fraction & Alb. & $\alpha_{1}$ & $\alpha_{2}$ & $\beta_{1}$ & $\beta_{2}$ & $\gamma$ & Ig./g \\
\hline I & $10^{*}$ & $4^{*}$ & $7^{*}$ & $11^{*}$ & $51^{*}$ & $17^{*}$ & 1.3 \\
II-III & 4 & - & 18 & 15 & 21 & 42 & 0.9 \\
IV-1 & 6 & - & 82 & 8 & 4 & - & 3.3 \\
IV-5 & 8 & 61 & 22 & 9 & - & - & 1.3 \\
IV-6 & 2 & 18 & 66 & 14 & - & - & 3.7 \\
IV-7 & 5 & - & 23 & 66 & 6 & - & 1.0 \\
IV-8 & 79 & 11 & 3 & 7 & - & - & 5.4 \\
IV-9 & 12 & - & 31 & 57 & - & - & 2.6 \\
V & 84 & 14 & -7 & 2 & - & - & 5.8 \\
Supernate V & 47 & 46 & 7 & - & - & - & 6.1
\end{tabular}

* Averages for Fractions I prepared during the past four years at the Massachusetts Public Health Biologic Laboratories. All other analyses were performed with the fractions derived from old plasma which were employed in the present studies. 
for measurement of total iodine $?$ (12). Protein concentrations were determined by a modified biuret procedure (13); the micro-Kjeldahl technique was used for nitrogen analyses.

3. Thyroxine-protein mixtures: One-tenth $\mathrm{ml}$. of saline containing the desired amounts of labelled and unlabelled thyroxine were added to $0.9 \mathrm{ml}$. of the various protein solutions. Mixtures of protein and thyroxine were permitted to stand for a minimum of thirty minutes at room temperature to assure binding equilibrium prior to zone electrophoresis. Fresh solutions of stable and radioactive thyroxine were prepared for each experiment. Similarly, freshly-drawn sera and freshly-dissolved Cohn Fractions were routinely employed even though thyroxinebinding was apparently not altered by storage in the deep-freeze. In all experiments, the final absolute concentration of organic iodine was determined by chemical analysis.

4. Paper electrophoresis: An apparatus designed in this laboratory was used. 8 It consisted of rectangular reservoirs of lucite which were enclosed on three sides by raised walls of lucite. When two reservoirs were apposed by approximating the slotted margins of their free side-walls and bases, a single enclosed rectangular chamber was formed which could be rendered air-tight by the addition of a peaked lucite cover. The "hanging strip" technique of Durrum (14) could then be employed by the insertion of a lucite rod through the overlapping side-walls above the two reservoirs. On the other hand, when the reservoirs were separated and two 33 by 38 by $2.5 \mathrm{~cm}$. glass plates resting horizontally upon a wooden support were placed between them, paper electrophoresis by the technique of Kunkel and Tiselius (15) could be performed. Buffer capacity of each reservoir was two liters and the reservoirs were subdivided into communicating compartments in order to separate the carbon electrodes from the major portion of buffer.

Large sheets of Whatman No. 3 filter paper were employed for zone electrophoresis. The sheets were moistened with buffer and blotted prior to introduction into the electrophoresis apparatus. Two-hundredths milliliter aliquots of protein solutions were applied onto the sheets in straight $1.6 \mathrm{~cm}$. lines separated from one another by marked intervals of $1.9 \mathrm{~cm}$.

Since 33 by $50 \mathrm{~cm}$. sheets were used in the Durrum system, nine specimens could be applied simultaneously. Applications were made directly upon the supporting rod or one inch beyond its anodal side. However, concurrent electrophoresis of multiple sheets was not feasible.

When the apparatus was adapted for electrophoresis by the method of Kunkel and Tiselius, 30 by $57 \mathrm{~cm}$. sheets of filter paper were employed, thus limiting the capacity to eight specimens per sheet. Mobilities in all eight specimens were identical (Figure 1). Therefore, the "plate glass" system could be employed for simultaneous electrophoresis of multiple sheets. This modification offered certain advantages. For example, quad-

\footnotetext{
${ }^{8}$ Constructed by Transplastics Fabricating Co., 295 Huntington Ave., Boston, Mass.
}

ruplicate analysis could be readily secured by successively applying $0.02 \mathrm{ml}$. aliquots from eight specimens to four sheets which were directly superimposed upon one another. Furthermore, by interposing sheets of "Parafilm" $\bullet$ between successive sheets of filter paper, four sets of eight different solutions, or a total of thirty-two separate specimens could be electrophoresed at one time. The use of plate-glass $2.5 \mathrm{~cm}$. in thickness obviated the need for equalizing pressure upon the filter paper by the use of clamps or other devices. Plates were covered with a thin coat of silicone ${ }^{10}$ and cellophane tape was used to seal the sides of the plates.

Test solutions were delivered onto the filter paper with calibrated hemoglobin pipettes. Adsorption to glass was standardized by the use of a fresh pipette for each application. A small amount of powdered bromphenol blue was added to the site of delivery for visualization of albumin during electrophoretic migration.

Barbital buffer at $\mathrm{pH} 8.6$, ionic strength 0.05 or acetate buffer at $\mathrm{pH} 4.5$, ionic strength 0.03 to 0.10 was employed. To minimize changes in buffer $\mathrm{pH}$, no buffer was used for more than a single experiment. In most studies, a potential of 117 volts was placed across the electrodes for twenty hours at room temperature. At $\mathrm{pH} 8.6$, migrations averaged 12 to $15 \mathrm{~cm}$. during this interval. Occasionally, voltages of 100 to 400 were employed for varying durations and maintained constant with a power supply and voltage regulator. Following electrophoresis, sheets were suspended in a drying rack in an oven at $130^{\circ} \mathrm{C}$. for ten minutes.

5. Protein localization and radioactive assay: Staining prior to counting resulted in sufficient smearing and elution of counts to diminish the subsequent accuracy of radioactive assay. On the other hand, satisfactory staining could not be secured by reapposing the segments of strip which had been partitioned for counting. Therefore, in every experiment, electrophoresis was performed on duplicate sheets.

One sheet was directly radioautographed in contact with No-Screen X-ray film and subsequently stained according to the method of Durrum (14). Where indicated, protein distribution was quantitated with a densitometer. ${ }^{11}$

The second sheet was divided into component strips. These strips were further cut into $1 \mathrm{~cm}$. segments beginning $1.5 \mathrm{~cm}$. cathodal to the point of application and extending $1.5 \mathrm{~cm}$. beyond the advancing albumin margin. Segments were counted in well-type scintillation counters containing crystal detector heads of thallium-activated sodium iodide.12 A minimum of 3000 counts, with a

\footnotetext{
9 "Parafilm": Marathon Corporation, Menasha, Wisc. 10 "Dri Film": General Electric, Silicone Products Department, Waterford, N. Y.

11 Model 501 A, Photovolt Corporation, 95 Madison Ave., New York, 16, N. Y.

12 Well-counters constructed by Macdonald Instrument Co., Cambridge, Mass. and N. Wood Counter Laboratory, Chicago, Ill.; strip scanner by Nuclear Instrument and Chemical Corp., Chicago, Ill.
} 
probable error of 2 to 3 per cent, were secured in segments which approximated background; 10,000 counts above background were secured with segments containing higher radioactivity. In later experiments, intact strips were counted with an automatic strip scanner. ${ }^{12}$

Radioactivity in each segment (expressed as a percentage of the total radioactivity present on the strip) was plotted upon arithmetic graph paper. Areas under the radioactive peaks were delineated by techniques similar to those of conventional schlieren analysis. The percentile distribution of radioactivity was determined by weight. For final orientation, reference was made to the radioautographic and staining patterns of the specimens on the undivided duplicate sheet.

\section{RESULTS}

\section{Methods}

Potential errors resulting from methodological artifacts were evaluated.

a) Adsorption to glassware: In protein-free, saline solutions, there was considerable adsorption of thyroxine (both labelled and unlabelled) to glassware. Adsorption was maximal with carrierpoor solutions of radiothyroxine and varied inversely with the surface area of the beakers and pipettes which were employed during preparative dilutions. From saline solutions calculated to contain 5 to $200 \mu \mathrm{g}$. per cent of added thyroxine, 60 to 40 per cent of the radiothyroxine was adsorbed to glassware. In the presence of proteins capable of binding thyroxine, adsorption was negligible.

b) Recovery of radiothyroxine: Loss of radiothyroxine during electrophoretic migration was assessed by comparing the total counts on electrophoresed strips with similar aliquots which had been applied onto filter paper but not electrophoresed. After electrophoresis of protein solutions for six to thirty hours at $\mathrm{pH} 8.6$ and 117 to 400 volts, the recovery of protein-bound radioactivity averaged $88.1 \pm 13.4^{13}$ per cent in 152 observations with the "plate-glass system"; in 13 experiments with the Durrum method, recovery averaged $91.6 \pm 10.9^{13}$ per cent. In 18 studies at $\mathrm{pH} 4.5,84.5 \pm 12.6^{13}$ per cent of the radioactivity could be accounted for in the area occupied by the proteins. Similar recovery experiments were performed with non-protein mixtures of thyroxine and saline. At $\mathrm{pH} 8.6$, in 5 studies, $67.4 \pm 2.6^{13}$ per cent of the radioactivity remained on the filter

\footnotetext{
13 Mean \pm Standard Deviation.
}

paper slightly anodal to the point of application; following electrophoresis of unbound thyroxine at $\mathrm{pH} 4.5$, radioactivity remained principally at the origin and recovery averaged 65.5 per cent.

c) Recovery of inorganic $I^{131}$ : Electrophoresis

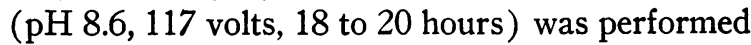
following the addition of $\mathrm{NaI}^{131}$ to protein solutions. With serum or with saline solutions of albumin or Cohn Fraction IV-6, recovery of carrier-free inorganic ${ }^{131}$ averaged 3.1 per cent; recoveries averaged 5.2 per cent when the protein solutions were supplemented with carrier to a final concentration of $200 \mathrm{mgm}$. per cent of inorganic iodide. In serum, the recovered radioactivity was principally confined to the albumin area. The data suggest that the presence of inorganic iodide (as a contaminant in the radiothyroxine or as a degradation product arising during electrophoresis) would not materially alter the electrophoretic partition of radioactivity.

d) Radiothyroxine: The electrophoretic distribution of other possible radioactive contaminants was not evaluated. For the following reasons, it seems unlikely that such impurities were present to any significant extent in fresh preparations of commercial radiothyroxine.

First, fresh radiothyroxine satisfied chromatographic criteria of homogeneity. Secondly, an identical partition of radioactivity between albumin and TBP was obtained when the specific activity of thyroxine-serum mixtures was varied five-fold and the total concentration of added thyroxine (i.e., the sum of both labelled and unlabelled material) was maintained constant at $25 \mu \mathrm{g}$. per cent.

However, during storage in vitro, significant degradation of radiothyroxine occurs. To minimize the effects of ageing, only fresh preparations were employed. Moreover, potential errors from degraded moieties were kept constant by adding equal amounts of radiothyroxine to both the control and experimental specimens in all subsequent studies.

e) Reproducibility of radioactive assay: Serum was labelled with radiothyroxine and varyingly supplemented with stable thyroxine. Multiple aliquots of each specimen were electrophoresed simultaneously and analyzed separately for the partition of radioactivity. At PBI concentrations of 8 to $122 \mu \mathrm{g}$. per cent, the variability in the distribution of albumin and TBP-bound radioactivity 
in quintuplicate analyses was not greater than \pm 5 per cent of the respective means for each category.

\section{Validation of experimental design}

Attempts to localize TBP in Cohn Fractions were based on the characteristics of the interaction between thyroxine and plasma proteins. Therefore, preliminary to an examination of Cohn Fractions, binding phenomena were studied in mixtures of serum and thyroxine.

a) Distribution of radiothyroxine: Sera from hyper-, hypo-, and euthyroid subjects were enriched with radiothyroxine and electrophoresed at $\mathrm{pH}$ 8.6. As others have shown (1-7), most of the labelled thyroxine localized with a moiety intermediate in mobility between the $\alpha_{1}$ and $\alpha_{2}$ globulins (Figure 1). A small but definite percentage of the radioactivity migrated with albumin even at the lowest concentrations of thyroxine. Eighty to 95 per cent of the radioactivity could be accounted for under the TBP and albumin peaks. Traces of radioactivity usually migrated ahead of the albumin area. The remaining radioactivity was varyingly distributed with the other anodal proteins and was concentrated principally in a narrow band, immediately ahead of the $\beta$ globulins. Cathodal migration with $\gamma$ globulin was never observed. In all sera, albumin-bound thyroxine progressively increased as the concentration of added thyroxine was augmented.

For the present, the significance of the apparent "spill-over" of thyroxine onto anodal components other than TBP or albumin cannot be assessed. Both in magnitude and pattern, it varied enormously. It could not be consistently augmented by increasing the concentration of thyroxine, although occasionally, it rose in parallel with the progressive elevation of albumin-bound radioac-

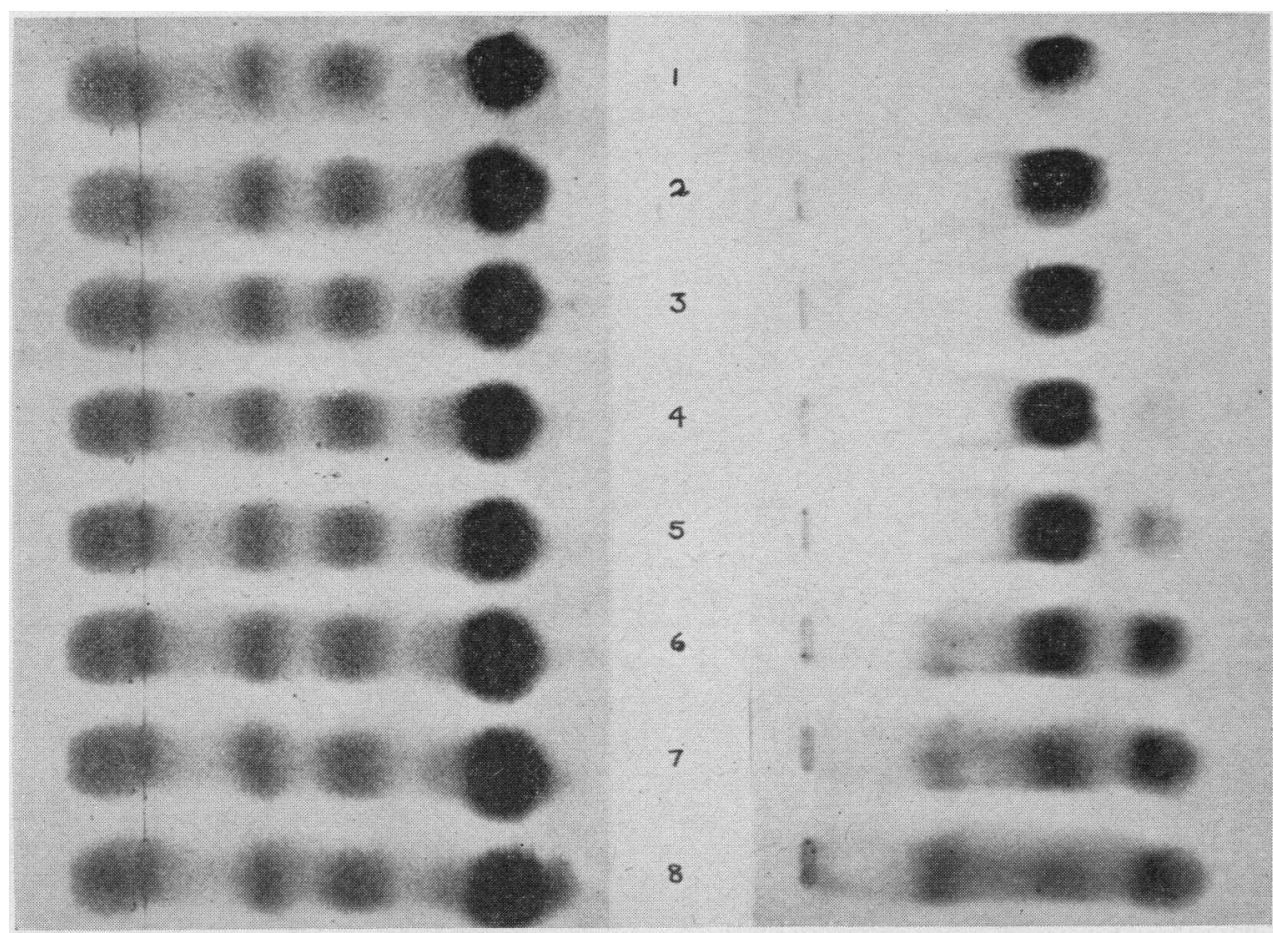

Fig. 1. Protein Bound Radioactivity at Various Concentrations of Thyroxine

Serum from a myxedematous subject (PBI $1.4 \mu \mathrm{g}$. per cent) was labelled with radiothyroxine, and PBI concentrations of $3.2,3.6,6.7,10.4,19.3,62,112$, and $194 \mu \mathrm{g}$. per cent were obtained in specimens 1 to 8 , respectively, by the addition of unlabelled L-thyroxine. Following electrophoresis at $\mathrm{pH} 8.6$, proteins were localized by staining with bromphenol blue. These are depicted on the left. The distribution of radioactivity is presented in the radioautographs on the right. The photograph does not clearly reproduce the definite amounts of albumin-bound radioactivity which could be discerned in specimens 1,2 , and 3 in the original radioautograph. As the PBI increases, progressive displacement of radioactivity from TBP to albumin occurs. 


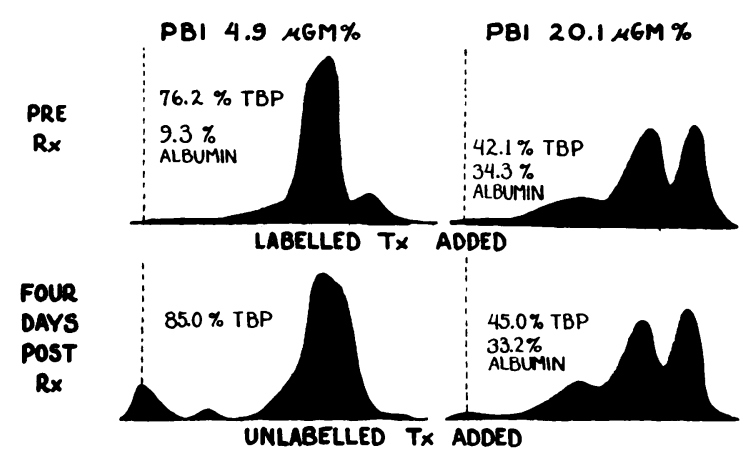

Fig. 2. Exchange of Protein-Bound Thyroxine

The upper two illustrations depict the distribution of radioactivity in serum to which radiothyroxine had been added in vitro; the serum shown in the lower illustrations was labelled endogenously with radiothyroxine which had been synthesized in vivo. In both sera, the concentrations or protein-bound iodine were adjusted by supplementation with stable L-thyroxine.

tivity (Figure 1). In some respects the phenomenon simulates the reported "trailing" due to adsorption of albumin during paper electrophoresis (16-18), and hence, it may merely represent methodological artifact. Despite these variations, the data indicate that albumin serves as the principal secondary carrier during the transport of thyroxine in serum.

b) Exchange of endogenous and exogenous thyroxine: Sera were obtained immediately before and four days after the administration of therapeutic doses of inorganic $\mathrm{I}^{131}$ for intractable angina pectoris. The thyroidal radiation was insufficient to liberate thyroglobulin into the circulation (19). Radiothyroxine was added to the non-radioactive sera obtained prior to therapy; the post-therapy sera were adjusted with stable L-thyroxine to identical concentrations of protein-bound iodine. Higher PBI levels were achieved by adding increasing amounts of stable thyroxine to aliquots of both the exogenously- and the endogenouslylabelled sera. A typical experiment can be seen in Figure 2. At a PBI concentration of $4.9 \mu \mathrm{g}$. per cent, an apparent difference may be noted in the partition of radioactivity following exogenous and endogenous labelling of sera. This difference is probably not significant. Concentrations of radioactivity in endogenously labelled sera were considerably less than in sera labelled exogenously. In the former group, albumin-bound radioactivity was not detected by direct counting. but could be clearly discerned in radioautographs. Thus, the percentage of TBP-bound radioactivity in the endogenously labelled serum at a PBI $4.9 \mu \mathrm{g}$. per cent is probably artifactually increased.

c) Reversibility of albumin-binding: Various techniques were employed to demonstrate that the distribution of thyroxine between TBP and albumin conforms to a reversible binding equilibrium.

Serum was labelled with radiothyroxine; an aliquot of this serum was supplemented with stable L-thyroxine to yield a PBI level of $201.5 \mu \mathrm{g}$. per cent. Intermediate concentrations of proteinbound iodine were obtained by combining the enriched and the unenriched specimens in various proportions. The mixtures were electrophoresed and the distributions of radioactivity were quantitated. The results indicated that thyroxine which is bound to albumin can be recovered onto TBP by simply decreasing the PBI without changing the absolute concentration of either TBP or albumin (Table II).

By modifying conventional electrophoretic techniques, the concentrations of TBP, albumin, and PBI within a single serum could be altered independently or in combination to assess the effects of each variable upon binding phenomena.

Sufficient amounts of L-thyroxine were added to serum so that radiothyroxine was equally partitioned between albumin and TBP. Electrophoresis was performed at $\mathrm{pH} 8.6$ in the "plateglass" system. The albumin zone was detached from the less rapidly migrating components. Unlabelled serum of similar or lower PBI content was applied onto the albumin spot and a second electrophoresis was performed. In each instance, partial displacement of albumin-bound radioac-

TABLE II

The effect of PBI dilution on the distribution of radiothyroxine in plasma*

\begin{tabular}{crcc}
\hline Specimen & $\begin{array}{c}\text { PBI } \\
(\mu g . \%)\end{array}$ & $\begin{array}{c}\text { \% with } \\
\text { TBP }\end{array}$ & $\begin{array}{c}\text { \% with } \\
\text { albumin }\end{array}$ \\
\hline 1 & 6.5 & 87.2 & 7.7 \\
2 & 12.6 & 80.6 & 11.5 \\
3 & 18.4 & 74.8 & 16.8 \\
4 & 30.9 & 69.9 & 25.3 \\
5 & 55.2 & 46.9 & 41.9 \\
6 & 104.0 & 28.5 & 50.3 \\
7 & 201.5 & 24.5 & 49.6 \\
\hline
\end{tabular}

* Specimens 1 and 7 mixed in varying proportions to obtain specimens $2-6$. 


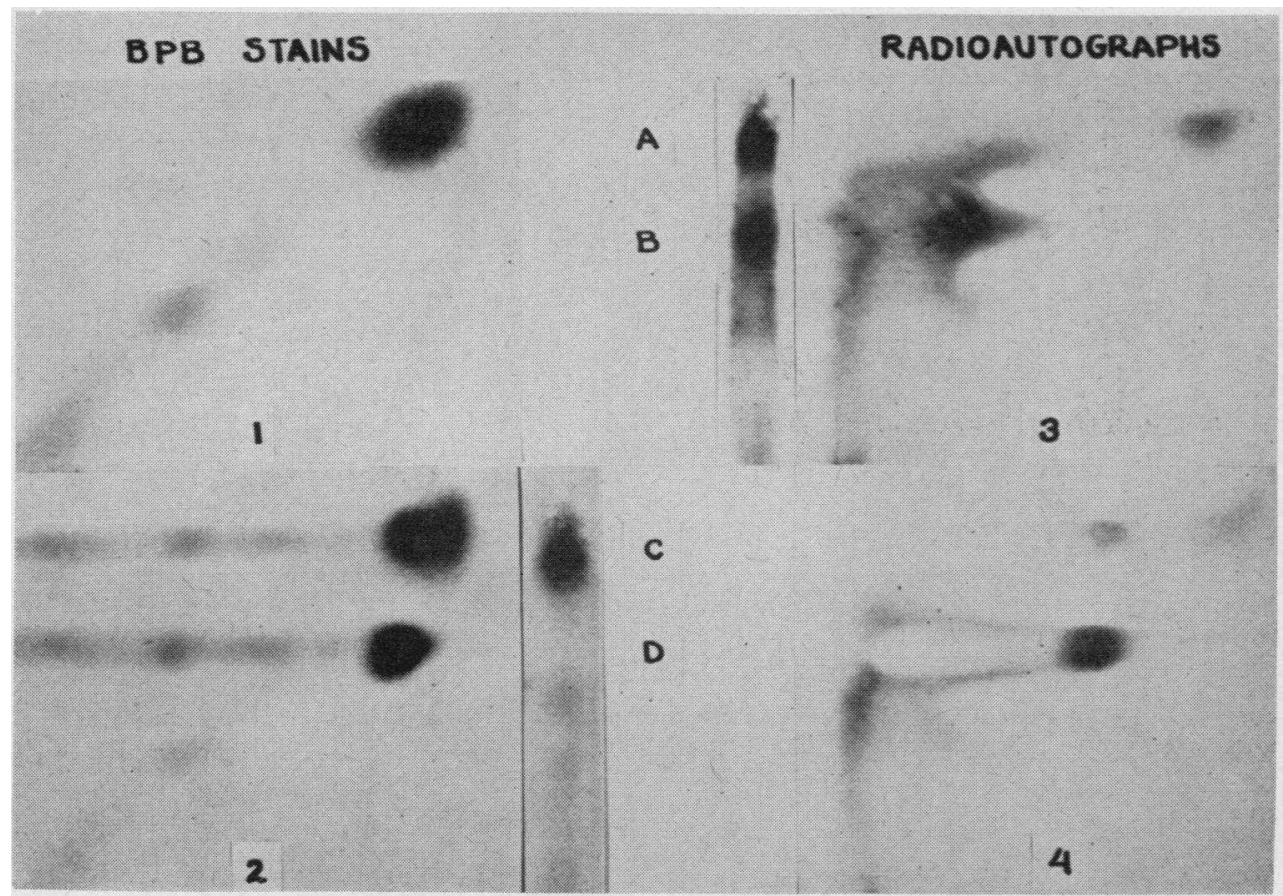

Fig. 3. Two-Dimensional Electrophoresis

Illustrations 1 and 3 represent the respective distributions of proteins and radioactivity in a labelled specimen of serum which was electrophoresed in two dimensions. Illustrations 2 and 4 represent a similar two-dimensional electrophoresis in which additional unlabelled serum was applied at sites corresponding to albumin and TBP prior to electrophoresis in the second dimension. The latter manipulation was performed by localizing albumin (A and $\mathrm{C}$ ) and TBP ( $B$ and $D$ ) with the aid of the two narrow strips of filter paper which are depicted in the center.

tivity onto the TBP of unlabelled serum could be demonstrated. No such partition occurred when the albumin was re-electrophoresed without the addition of unlabelled serum.

Similar results were obtained with "two-dimensional electrophoresis" (Figure 3). Herein, serum labelled with radiothyroxine was applied onto two sites spaced $13 \mathrm{~cm}$. apart on a 26 by 57 $\mathrm{cm}$. sheet of filter paper. For purposes of control, similar aliquots were applied onto two appended 2.5 by $57 \mathrm{~cm}$. strips of filter paper. One dimensional electrophoresis was performed by the Kunkel-Tiselius method following which the appended strips were removed. One of them was radio-autographed. The second strip was rapidly dried and stained. With the stained strip for reference, protein moieties in the two bands on the large sheet of filter paper could be localized. Accordingly, the areas corresponding to TBP and albumin in one of these bands were supplemented with $0.020 \mathrm{ml}$. specimens of unlabelled serum.
Electrophoresis in the second dimension was then performed by turning the entire sheet 90 degrees and by bridging it to the buffer reservoirs with fresh filter paper. It was found that TBP of the added unlabelled serum could abstract most of the radioactivity which, initially, had migrated with albumin. On the other hand, a shift in the distribution of radioactivity was not observed in the control band which had not been supplemented with serum prior to the second electrophoresis.

d) Conclusion: In serum, endogenous and exogenous thyroxine are in ready exchange; thyroxine is distributed among plasma proteins according to a reversible binding equilibrium between TBP and secondary carriers of lesser affinity; displacement onto secondary carriers (principally albumin) occurs with increasing thyroxine concentrations; and displaced thyroxine can be recovered onto TBP by decreasing the concentration of thyroxine or by increasing the availability of TBP. 
TABLE III

The effect of added Cohn Fractions on the distribution of radiothyroxine in serum

\begin{tabular}{|c|c|c|c|c|}
\hline \multirow[b]{2}{*}{ Fraction } & \multicolumn{2}{|c|}{ Fractions from fresh plasma } & \multicolumn{2}{|c|}{ Fractions from old plasma } \\
\hline & $\%$ with TBP & $\%$ with alb. & $\%$ with TBP & $\%$ with alb. \\
\hline Serum control & $42.6 \pm 3.0(7)^{*}$ & $44.4 \pm 2.1(7)^{*}$ & $34.2 \pm 0.9(5) \dagger$ & $49.3 \pm 2.9(5) \dagger$ \\
\hline $\begin{array}{l}\text { Serum + I } \\
\text { Serum + II-III } \\
\text { Serum + IV-1 } \\
\text { Serum + IV-5 } \\
\text { Serum + IV-6 } \\
\text { Serum + IV-7 } \\
\text { Serum + IV-8 } \\
\text { Serum + IV-9 } \\
\text { Serum + V } \\
\text { Serum + Super. V }\end{array}$ & $\begin{array}{l}40.9 \\
42.1 \\
45.6 \\
57.9 \\
78.8 \\
54.3 \\
55.7 \\
65.6 \\
43.8 \\
39.8\end{array}$ & $\begin{array}{l}44.9 \\
43.9 \\
44.7 \\
31.5 \\
15.0 \\
37.0 \\
34.3 \\
26.6 \\
47.2 \\
46.7\end{array}$ & $\begin{array}{l}32.4 \\
34.3 \\
34.5 \\
58.9 \\
74.4 \\
47.2 \\
51.8 \\
61.4 \\
33.5 \\
32.9\end{array}$ & $\begin{array}{l}54.1 \\
51.7 \\
55.6 \\
30.3 \\
18.0 \\
41.4 \\
39.0 \\
30.4 \\
54.6 \\
53.6\end{array}$ \\
\hline
\end{tabular}

* The concentration of PBI in the serum of an euthyroid subject (J. P.) was adjusted to $50.0 \mu \mathrm{g}$. per cent. The figures in parentheses denote the number of simultaneous electrophoreses which were performed to derive standard deviations for the distribution of radioactivity prior to the addition of Cohn Fractions which had been obtained from fresh plasma.

$\dagger$ The concentration of PBI in the serum of an euthyroid subject (N. F.) was adjusted to $46.6 \mu$ g. per cent. Added Cohn Fractions were prepared from outdated blood-bank blood.

\section{Cohn Fractions}

The foregoing observations formed the basis for testing Cohn Fractions.

a) Mixtures of Cohn Fractions and serum: Labelled and unlabelled thyroxine were added to sera to yield concentrations of protein bound iodine ranging from 26 to $90 \mu \mathrm{g}$. per cent. At these PBI levels, radiothyroxine was varyingly partitioned between TBP and albumin. Twentyseven mgm. amounts of lyophilized Cohn Fractions were dissolved in $1 \mathrm{ml}$. aliquots of the sera $;{ }^{14}$ no attempt was made to correct for insoluble materials. Concurrent paper electrophoreses were performed with sera containing added Cohn Fractions (circa $2.7 \mathrm{Gm}$. per cent) and with at least four control specimens to which extra protein had not been added. It was anticipated that albuminbound thyroxine might be recovered from albumin onto TBP by Cohn Fractions containing ratios of $\mathrm{TBP} /$ albumin greater than the normal serum proportions.

The partition of radioactivity was not altered by Cohn Fractions I, II-III, IV-I, V, and Supernate $\mathrm{V}^{15}$ (Table III). However, all sub-groups

\footnotetext{
${ }^{14}$ Heparin was added to prevent clotting in all experiments involving Cohn Fraction I.

15 Currently, Fraction VI is concentrated with zinc hydroxide (28) from the supernatant solution which remains after the precipitation of Fraction $\mathrm{V}$ according to the low temperature-low salt-ethanol fraction method (8). Preliminary evidence would indicate that zinc re-
}

of Fraction IV-4 (i.e., IV-5, IV-6, IV-9; and IV-7, IV-8) significantly diminished the radioactivity in the albumin area and enhanced the apparent binding of thyroxine by TBP. Fractions IV-6 and IV-9 produced the most pronounced augmentation of TBP activity. Age of the parent plasma did not affect results. Findings were similar with Cohn Fractions derived from outdated blood bank plasma as well as from fresh plasma (Table III).

b) Mixtures of Cohn Fractions and saline: Lyophilized Cohn Fractions were dissolved in isotonic saline ${ }^{14}$ and repeatedly centrifuged to remove all insoluble denatured material. Biuret analyses were performed to adjust the protein concentration in all solutions to 2.0 gram per cent. Control specimens of serum were diluted to a comparable extent. At $\mathrm{pH} 8.6$, the components of the various Cohn Fractions retained their characteristic electrophoretic mobilities. Thus, for purposes of reference, the migration of radioactivity could be related to simultaneously electrophoresed specimens of serum.

duces the quantity of thyroxine bound by TBP (20). Therefore, attempts were made to obtain the proteins of Fraction VI without zinc precipitation.

Excess salts and ethanol in Supernate $\mathrm{V}$ were removed by dialysis against repeated changes of distilled water at $4^{\circ} \mathrm{C}$. The dialyzed Supernate V was lyophilized and the recovered proteins were employed in subsequent experiments. Similar dialysis and lyophilization did not diminish the binding of thyroxine by Cohn Fraction IV-6. 
Studies were designed to demonstrate trace amounts of thyroxine-binding proteins and to compare their relative abundances on the basis of saturation characteristics. Low concentrations of carrier thyroxine were employed to meet the first objective. The PBI concentration in all solutions was adjusted to $11.4 \mu \mathrm{g}$. per cent with stable and labelled L-thyroxine. Paper electrophoresis at $\mathrm{pH} 8.6$ was performed and the distribution of radioactivity was quantitatively assessed (Figure 4, Column 1). Radioactivity in saline solutions of Cohn Fractions I and II-III extended from the origin to a zone immediately ahead of the $\beta$ globulins. Contrariwise, some of the radioactivity in Fractions IV-1, IV-7, $\mathrm{V}^{\circ}$ and Supernate $\mathrm{V}$, and all of the radioactivity in Fractions IV-5, IV -6, IV-8, and IV-9 migrated in parallel with the TBP of serum. Staining with bromphenol blue was not appreciable in any of these areas of concentrated radioactivity.

For comparison of relative binding capacities, the concentration of protein-bound iodine in all solutions was augmented to $71.4 \mu \mathrm{g}$. per cent with unlabelled thyroxine (Figure 4, Column 2). Such loading did not alter the diffuse distribution of radioactivity in solutions containing either Cohn
Fractions I or II-III. On the other hand, in the control sample of serum, most of the radioactivity was displaced from the TBP onto albumin. Similarly, in all Cohn Fractions other than I and IIIII, the addition of large amounts of thyroxine caused partial or complete "spill-over" of radioactivity onto secondary carriers. Proteins other than albumin served as secondary carriers in fractions which were deficient in albumin. Displacement was least in solutions containing IV-6 or IV -9 and most of the radioactivity remained confined to a discrete zone corresponding in electrophoretic mobility at $\mathrm{pH} 8.6$ to the TBP of serum.

The specificity of thyroxine-binding in IV-6 and IV-9 was assessed by electrophoresis in acetate buffer at $\mathrm{pH} 4.5$ (Figure 5). At this $\mathrm{pH}$, free radiothyroxine or radiothyroxine combined with Cohn Fraction II-III remained at the origin. Labelled TBP in thyroxine-serum mixtures migrated towards the anode in confirmation of the report of Robbins, Petermann, and Rall (21). The radioactivity in solutions containing Fractions IV-6 and IV-9 also migrated slowly towards the positive pole despite the predominant cathodal movement of most of the other proteins.

c) Mirtures of Cohn Fractions, saline and

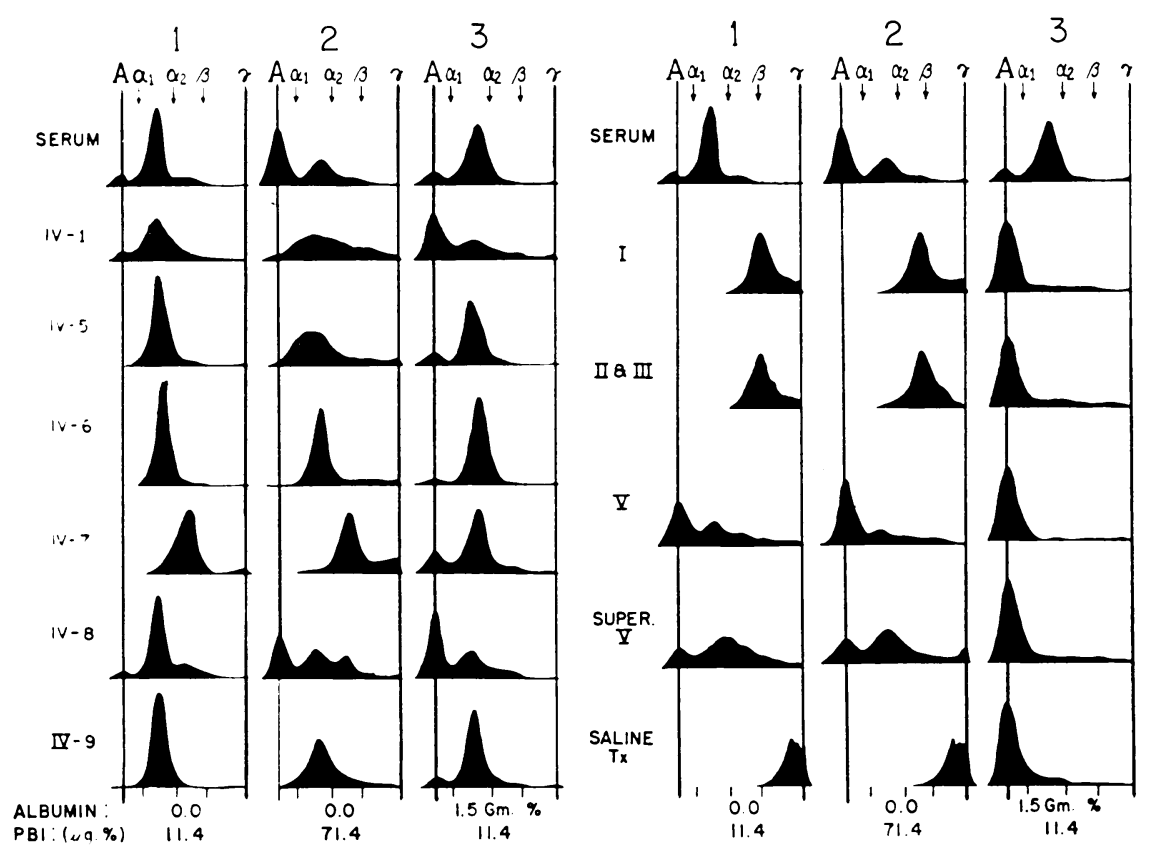

Fig. 4. Thyodine Binding by Cohn Fractions

The darkened areas represent the distribution of radioactivity following paper electrophoresis. 


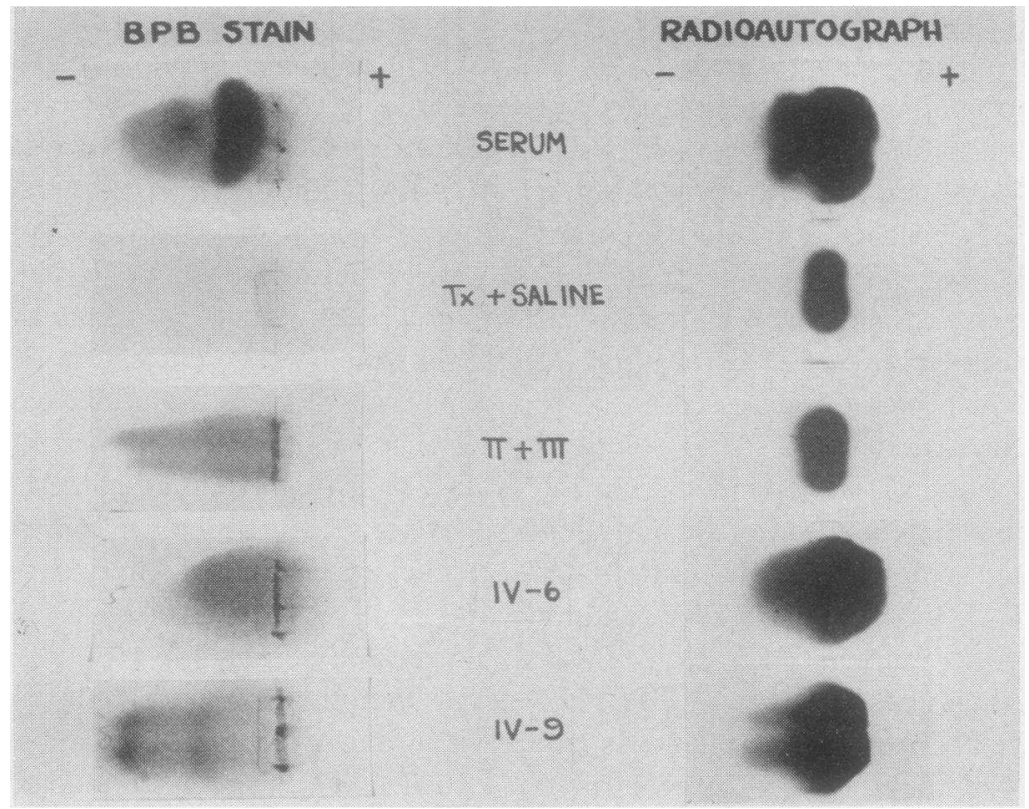

Fig. 5. ZoNe Electrophoresis at pH 4.5

The similarities in the anodal migrations of serum TBP and the thyroxinebinding moieties in Fractions IV- 6 and IV- 9 can be seen in the radioautographs on the right.

mercaptalbumin: To simulate the inter-relationships of proteins in serum and to compensate for the variable content of albumin in Cohn Fractions, attempts were made to electrophorese Cohn Fractions in association with constant amounts of added albumin. It was hoped that such combination might provide further quantitative comparison of the thyroxine-binding moieties in Cohn Fractions. Albumin preparations whose homogeneity ranged from 94 to 100 per cent by moving boundary electrophoresis were tested for the presence of non-albumin contaminants capable of binding thyroxine. Only mercaptalbumin (22) ${ }^{16} \mathrm{did}$ not contain detectable traces of a material which resembled serum TBP during paper electrophoresis at $\mathrm{pH}$ 8.6. Therefore, saline solutions of Cohn Fractions (Protein : $1.85 \mathrm{Gm}$. per cent; PBI : 11.4 $\mu \mathrm{g}$. per cent) were supplemented with weighed amounts of lyophilized mercaptalbumin (15 mgm.

\footnotetext{
16 Mercaptalbumin which had been dialyzed against cysteine to remove mercury was kindly provided by $\mathrm{Dr}$. Margaret J. Hunter of the Department of Biophysical Chemistry of Harvard Medical School. The albumin preparations which contained TBP-like impurities included crystalline bovine albumin and various reworked preparations of Fraction V.
}

per ml.) prior to paper electrophoresis at $\mathrm{pH}$ 8.6. All of the radioactivity in solutions containing Fractions I, II-III, V, and Supernate V migrated with the added albumin (Figure 4, Column 3). Lesser changes were effected in mixtures containing the other Cohn Fractions. The distribution of radioactivity was least altered in the presence of IV-6 or IV -9.

d) Conclusions: All Cohn Fractions which are precipitated subsequent to Fraction III contain detectable amounts of material which binds thyroxine and which simulates the electrophoretic mobility of serum TBP at $\mathrm{pH}$ 8.6. This material is most abundantly present in Fractions IV-6 and IV-9. On the basis of electrophoresis at $\mathrm{pH} \mathrm{4.5}$, it may be inferred that the thyroxine-binding moieties in IV- 6 and IV -9 are indeed the same as the TBP of serum.

\section{DISCUSSION}

Earlier attempts to localize TBP in Cohn Fractions of plasma have followed several lines. By dialysis, it has been shown that thyroxine-binding is minimal with gamma globulin (23). However, 
since thyroxine is bound, at least partly, by all proteins, the dialysis technique affords limited specificity. Other investigators have relied upon measurements of iodine/nitrogen ratios $(23,24)$. With this approach, Salter meticulously localized the thyroxine-transport protein in Fractions IV and $\mathrm{V}$, and even succeeded in specifically implicating the subfractions of IV which were rich in alpha globulins (i.e., IV-5 and IV-6) (25). However, the differences among various fractions were small and inconsistent, and it is likely that some of the variability may have resulted from artifacts intrinsic to the fractionation technique. During fractionation by Method 6 of Cohn, disruption of thyroxine-protein bonds and reagent contamination may progressively increase the content of unbound inorganic and organic iodine in the alcohol-protein-electrolyte mixtures. That coprecipitation and occlusion of these iodine moieties does occur is suggested by the routine demonstration of significant amounts of proteinbound iodine in fractions which do not contain detectable amounts of TBP such as Fractions I or II-III (23-25). Errors thereby introduced would become especially manifest in fractions which are precipitated last, either in great bulk (cf. Fraction $\mathrm{V}$ ) or in small amounts from large volumes of suspending solution ( $c f$. Fraction VI). It is of interest in this connection that high iodine/nitrogen ratios have been reported for Fraction V (23$25)$ and for Fraction VI $(25,26)$ although their content of TBP would appear to be small.

Obviously, it would be most desirable to measure TBP directly. As yet, no such technique has been evolved. In the present experiments, attempts were made to minimize the difficulties which are inherent in indirect approaches. Fractions prepared by Methods 6 of Cohn were compared by a variety of saturation and competitivebinding techniques; zone electrophoresis was employed to provide specificity.

It may be argued that saturation characteristics cannot be used for intercomparisons since the fractionation technique, per se, may varyingly desaturate or remove endogenous thyroxine from the different Cohn Fractions. Although this possibility cannot be excluded, it would seem unlikely that variation in endogenous hormone (e.g., iodine/protein ratios; Table I) could significantly affect the results obtained in systems wherein the concentration of added carrier thyroxine was greater than $100 \mu \mathrm{g}$. per cent (v.s.).

Certain properties of TBP were noted in the course of the present experiments. It may be inferred that the TBP of Fraction IV- 6 is not a lipoprotein; multiple freezings and thawings did not alter its binding characteristics. TBP is highly soluble in water, and neither solubility nor thyroxine-binding were diminished by dialyzing IV-6 against repeated changes of distilled water to remove occluded inorganic moieties. The stability of TBP is evidenced by the observation that fractions derived from fresh and from outdated blood did not appreciably differ in activity.

Zinc interferes with the interaction of thyroxine and TBP in serum and in Fractions IV-6 and IV-9. Conceivably, therefore, the techniques described above may not be applicable to proteins which have been prepared by zinc precipitation. Among these proteins may be included the products of Method 10 of Cohn and his co-workers (27) and the pure $\alpha$ glycoproteins of Schmid (28, 29).

Throughout this report, the term TBP has been employed to designate the thyroxine-binding protein of plasma. It should be stressed that nomenclatural selection of the singular is arbitrary and intended solely for convenience. By labelling the TBP in serum with radiothyroxine, Petermann, Robbins, and Hamilton have derived an ultracentrifugal sedimentation constant for TBP (30), and Robbins, Petermann, and Rall (21) have shown that the electrophoretic mobility of TBP at $\mathrm{pH} 4.5$ simulates that of the $\mathrm{M}-2$ glycoproteins of Mehl, Golden, and Winzler (31). However, to date, TBP has not been isolated. Thus, despite all physicochemical measurements, it cannot be said whether TBP represents only one protein or several proteins which, in protein mixtures, exhibit similar electrophoretic and ultracentrifugal characteristics. Furthermore, if TBP is a single protein, the possibility of multiple sites for thyroxine-binding cannot be excluded. Because of these considerations, the present data have been subjected only to descriptive analysis. It was felt that available information did not justify more quantitative treatment, and that precise stoichiometrical formulations must await the availability of pure TBP. 


\section{SUMMARY}

The interactions between thyroxine and plasma proteins have been investigated with paper electrophoresis. The observations furnished an experimental basis for multiple techniques designed to localize the thyroxine-binding protein (TBP) in fractions of plasma prepared by Method 6 of Cohn. It has been demonstrated that Cohn Fractions IV- 6 and IV -9 constitute the most abundant sources of TBP.

\section{ACKNOWLEDGMENTS}

The technical assistance of Miss Barbara Fine is gratefully acknowledged. The authors are greatly indebted to Dr. Robert B. Pennell and Dr. John L. Oncley of the Department of Biophysical Chemistry of Harvard Medical School and to Dr. John M. Newell and Mr. Roderick C. Dwyer of the Massachusetts Public Health Biologic Laboratories. This study could not have been undertaken without their constant encouragement and generosity in making laboratory space available to us.

\section{REFERENCES}

1. Gordon, A. H., Gross, J., O'Connor, D., and PittRivers, R., Nature of the circulating thyroid hormone-plasma protein complex. Nature, 1952, 169, 19.

2. Larson, F., Deiss, W. P., and Albright, E. C., Localization of protein-bound radioactive iodine by filter paper electrophoresis. Science, 1952, 115, 626.

3. Winzler, R. J., and Notrica, S. R., Association of thyroxine with plasma proteins. Federation Proc., 1952, 11, 312.

4. Deiss, W. P., Albright, E. C., and Larson, F. C., A study of the nature of the circulating thyroid hormone in euthyroid and hyperthyroid subjects by use of paper electrophoresis. J. Clin. Invest., 1952, 31, 1000.

5. Robbins, J., and Rall, J. E., Zone electrophoresis in filter paper of serum $I^{\text {sts }}$ after radioiodide administration. Proc. Soc. Exper. Biol. \& Med., 1952, 81, 530.

6. Horst, W., and Rösler, H., Der Transport des Hormonjods im menschlichen Serum untersucht mit Papierelektrophorese und Radiojod. Zugleich ein Beitrag zur Frage der Existenz von sog. Zwischenfraktionen. Klin. Wchnschr., 1953, 31, 13.

7. Larson, F. C., Deiss, W. P., and Albright, E. C., Radiochromatographic identification of thyroxin in an alpha globulin fraction of serum separated by starch zone electrophoresis. J. Clin. Invest., 1954, 33, 230.
8. Cohn, E. J., Strong, L. E., Hughes, W. L., Jr., Mulford, D. J., Ashworth, J. N., Melin, M., and Taylor, H. L., Preparation and properties of serum and plasma proteins. IV. A system for the separation into fractions of the protein and lipoprotein components of biological tissues and fluids. J. Am. Chem. Soc., 1946, 68, 459.

9. Surgenor, D. M., Strong, L. E., Taylor, H. L., Gordon, R. S., Jr., and Gibson, D. M., The separation of choline esterase, mucoprotein, and metal-combining protein into subfractions of human plasma. J. Am. Chem. Soc., 1949, 71, 1223.

10. Gleason, G. I., Some notes on the exchange of iodine with thyroxine homologues. J. Biol. Chem., 1955, 213, 837.

11. Barker, S. B., Humphrey, M. J., and Soley, M. H., The clinical determination of protein-bound iodine. J. Clin. Invest., 1951, 30, 55.

12. Barker, S. B., Determination of protein-bound iodine. J. Biol. Chem., 1948, 173, 715.

13. Mehl, J. W., The biuret reaction of proteins in the presence of ethylene glycol. J. Biol. Chem., 1945, $157,173$.

14. Durrum, E. L., A microelectrophoretic and microionophoretic technique. J. Am. Chem. Soc., 1950, 72, 2943.

15. Kunkel, H. G., and Tiselius, A., Electrophoresis of proteins on filter paper. J. Gen. Physiol., 1951, 35, 89.

16. Slater, R. J., and Kunkel, H. G., Filter paper electrophoresis with special reference to urinary proteins. J. Lab. \& Clin. Med., 1953, 41, 619.

17. Freinkel, N., Schreiner, G. E., Athens, J. W., Hiatt, C. W., and Breese, S., Artifactual differences in the distribution of T-1824 and $\mathrm{I}^{12}$-labeled albumin resulting from mixing prior to administration. J. Lab. \& Clin. Med., 1954, 43, 215.

18. Gabrieli, E. R., Goulian, D., Jr., Kinersly, T., and Collet, R., Zone paper electrophoresis studies on radio-iodinated human serum albumin. J. Clin. Invest., 1954, 33, 136.

19. Robbins, J., Rall, J. E., Becker, D. V., and Rawson, R. W., The nature of the serum iodine after large doses of $I^{121}$. J. Clin. Endocrinol., 1952, 12, 856.

20. Freinkel, N., Dowling, J. T., and Ingbar, S. H., Unpublished observations.

21. Robbins, J., Petermann, M. L., and Rall, J. E., Electrophoresis of the thyroxine-binding protein of serum at $\mathrm{pH}$ 4.5. J. Biol. Chem., 1955, 212, 403.

22. Hughes, W. L., Jr., An albumin fraction isolated from human plasma as a crystalline mercuric salt. J. Am. Chem. Soc., 1947, 69, 1837.

23. Taurog, A., and Chaikoff, I. L., The nature of the circulating thyroid hormone. J. Biol. Chem., 1948, 176, 639.

24. Salter, W. T., The metabolic circuit of the thyroid hormone. Ann. New York Acad. Sc., 1949, 50, 358. 
25. Salter, W. T., Unpublished data included in the minutes of the weekly luncheon meetings of the Harvard University Laboratory of Physical Chemistry Related to Medicine and Public Health, 1944 1950.

26. Schmid, K., Preparation and properties of serum and plasma proteins. XXIX. Separation from human plasma of polysaccharides, peptides and proteins of low molecular weight. Crystallization of an acid glycoprotein. J. Am. Chem. Soc., 1953, 75, 60.

27. Cohn, E. J., Gurd, F. R. N., Surgenor, D. M., Barnes, B. A., Brown, R. K., Derouaux, G., Gillespie, J. M., Kahnt, F. W., Lever, W. F., Liu, C. H., Mittelman, D., Mouton, R. F., Schmid, K., and Uroma, E., A system for the separation of the components of human blood: quantitative procedures for the separation of the protein components of human plasma. J. Am. Chem. Soc., 1950, 72, 465.

28. Schmid, K., Isolation of a group of $\alpha_{2}$-glycoproteins from human plasma. J. Am. Chem. Soc., 1955, 77, 742.

29. Schmid, K., Isolation and characterization of glycoproteins from human plasma. J. Am. Chem. Soc., 1953, 75, 2532.

30. Petermann, M. L., Robbins, J., and Hamilton, M. G., Sedimentation of the thyroxine-binding protein of serum in the partition cell. J. Biol. Chem., 1954, 208, 369.

31. Mehl, J. W., Golden, F., and Winzler, R. J., Mucoproteins of human plasma. IV. Electrophoretic demonstration of mucoproteins in serum at $\mathrm{pH} 4.5$. Proc. Soc. Exper. Biol. \& Med., 1949, 72, 110. 